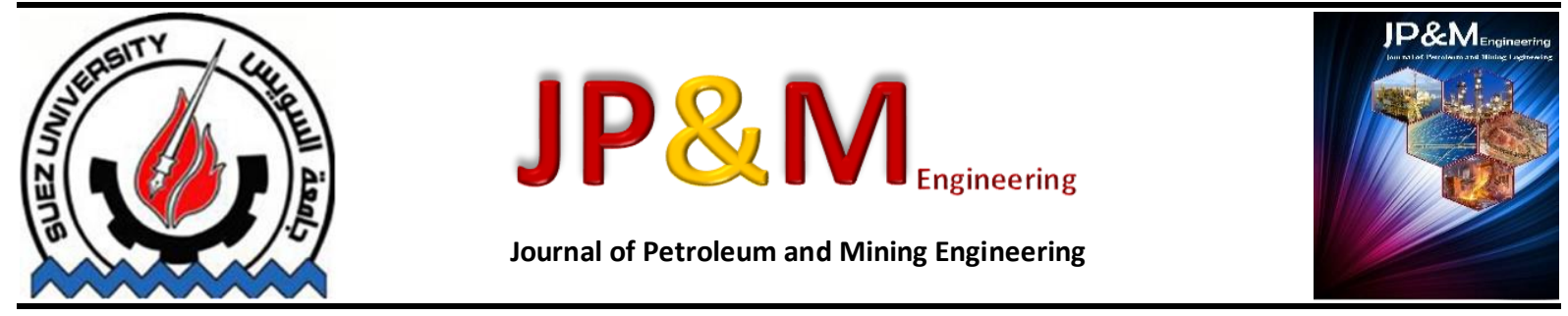

\title{
Effect of HYL Process Parameters on the Quality of Iron Ore Reduction
}

\author{
M.M.I.Ahmed ${ }^{1}$, M.A.Shahin ${ }^{2}$ M.A.Elzeky ${ }^{2}$ M.M.Z. Ahmed ${ }^{2,3}$ \\ ${ }^{1}$ Suez Steel Company, Add: Egypt, Suez, Attaka, Adabeyah road. \\ ${ }^{2}$ Department of Metallurgical and Materials Engineering, Suez University, Suez 43512 \\ ${ }^{3}$ Department of Mechanical Engineering,The British University in Egypt, El-Sherouk City, 11837 Cairo, Egypt
}

Abstract

In this work the effect of a number of HYL process parameters on direct reduced iron (DRI) quality, during a real process taking place at Suez Steel Company have been studied. These parameters are gas temperature at reactor inlet and at heater outlet, process gas flow rate, oxygen flow rate at partial combustion zone, reducing gases ratio, humidity percent in process gas, cooling gas flow rate and natural gas make-up for cooling gas. By changing these parameters, then by calculating the DRI quality (metallization and carbon content

\section{Keywords}

HYL Zero Reformer Process, Iron Ore Reduction percentages ) after the residence time, I has been found that the metallization degree increases with the increase of gas temperature at reactor inlet and at heater outlet, process gas flow, oxygen flow at partial combustion zone, reducing gases ratio, humidity percent in process gas. Also increasing of cooling gas flow rate and natural gas make-up for cooling gas has caused increase a carbon content.

\section{Introduction}

In the direct reduction processes, iron ore is reduced with reducing gases at high temperature that remove the oxygen from iron oxides. Direct Reduced Iron (DRI). Reducing gases and the temperature at which the reducing reactions take place depend on the Direct Reduction Process, but the temperature never reaches the melting point of the solid. HYL and Midrex are the commercially processes most applied to produce DRI [1]. The main reducing gases used in direct reduction processes are: Hydrogen and Carbon Monoxide. Due to the thermodynamics of the direct reduction reactions which are almost endothermic, reducing gases are heated up to temperatures between $750{ }^{\circ} \mathrm{C}$ and $1100{ }^{\circ} \mathrm{C}$, Therefore, the iron ore should be preheated from room temperature up to the reaction temperature [1]. Reducing gases are generated by the reaction between an organic fuel and an oxidizer, producing gaseous mixtures made of Hydrogen and Carbon Monoxide [2].

The HYL Process is up to date the latest technological development for direct reduction processes. It is used to convert iron ores in metallic iron, Direct Reduced Iron (DRI) or sponge iron. The quality of the produced DRI is determined by both metallization degree and carbon content [3]. In HYL plant, the reducing gas source may be: Natural Gas, coke oven gas, Syn-Gas or any gas containing enough amount of hydrocarbons, Hydrogen or Carbon Monoxide. For all cases, the process configuration is always the same. The objective of this work is to study the effect of some of HYL-3 process parameters on the quality of DRI in terms of metallization degree and carbon content in Suez steel company Direct reducing plant.

\section{Industrial Experimental Procedures and Terminologies}

In the following sections the experimental procedure to examine the effect of various parameters will be explained.

\section{A. Direct reduced iron quality}

The DRI quality is determined by the following [5]:

A-1 Metallization degree (M \%) [5]:

$\mathrm{M} \%=(\%$ Metallic Fe $/$ \%Total Fe $) * 100=90-94 \%$

A-2 Carbon content (C\%)[5] :

It can be $1.5-4 \%$

\section{B. Reduction reactions}

The thermodynamics an iron ore reduction deals primariy with energy transfer and the chemical equilibrium between its oxides and the reducing agents.

B-1 Reduction with Carbon Monoxide (CO)

The overall reaction of iron oxide with $\mathrm{CO}$ at temperatures above $570^{\circ} \mathrm{C}$ which has exothermic nature is as follows:

$\mathrm{Fe}_{2} \mathrm{O}_{3}+3 \mathrm{CO} \rightarrow 2 \mathrm{Fe}+3 \mathrm{CO}_{2}$ 


\section{B-2 Reduction with Hydrogen $\left(\mathrm{H}_{2}\right)$}

The overall reaction of iron oxides with $\mathrm{H}_{2}$ is practically the same as with carbon monoxide, but has an endothermic nature.

$\mathrm{Fe}_{2} \mathrm{O}_{3}+3 \mathrm{H}_{2} \rightarrow 2 \mathrm{Fe}+3 \mathrm{H}_{2} \mathrm{O}$ (g)

\section{B-3 Reaction Kinetics}

The importance of chemical kinetics for direct reduction processes is in the fact that the productivity of these processes has a direct relationship with the reaction kinetics [9].

\section{Carburization reaction}

In a reduction process, in addition to reducing the iron ore, it is important to deposit, in a controlled form, a certain amount of carbon in the reduced iron that will be beneficial for steelmaking.

The carburization of direct reduced iron takes place by the action of certain gases, commonly called carburization agents, among which, carbon monoxide $(\mathrm{CO})$ and methane $\left(\mathrm{CH}_{4}\right)$ are the most important.

The carburization reactions by $\mathrm{CO}$ and $\mathrm{CH}_{4}$ in a direct reduction process are the following:

\section{C-1 Carburization with $\mathrm{CO}$}

$$
\begin{aligned}
& 3 \mathrm{Fe}(\mathrm{s})+2 \mathrm{CO}(\mathrm{g}) \rightarrow \mathrm{Fe}_{3} \mathrm{C}(\mathrm{s})+\mathrm{CO}_{2}(\mathrm{~g}) \\
& 2 \mathrm{CO}(\mathrm{g}) \rightarrow \mathrm{C}(\mathrm{s})+\mathrm{CO}_{2}(\mathrm{~g}) \\
& \mathrm{CO}(\mathrm{g})+\mathrm{H}_{2}(\mathrm{~g}) \rightarrow \mathrm{C}(\mathrm{s})+\mathrm{H}_{2} \mathrm{O}(\mathrm{g})
\end{aligned}
$$

These three reactions are exothermic, and therefore, they will have a greater chemical potential when they occur at low temperatures. Studies of reaction kinetics indicate that these reactions have a better yield from $500{ }^{\circ} \mathrm{C}$ to $700^{\circ} \mathrm{C}$ due to a higher reaction velocity at this temperature range [3].

\section{C-2 Carburization with $\mathrm{CH}_{4}$}

$$
\begin{aligned}
& 3 \mathrm{Fe}(\mathrm{s})+\mathrm{CH}_{4}(\mathrm{~g}) \rightarrow \mathrm{Fe}_{3} \mathrm{C}(\mathrm{s})+2 \mathrm{H}_{2}(\mathrm{~g}) \\
& \mathrm{CH}_{4}(\mathrm{~g}) \rightarrow \mathrm{C}(\mathrm{s})+2 \mathrm{H}_{2}(\mathrm{~g})
\end{aligned}
$$

Thermodynamics and chemical kinetics show that these reactions are also endothermic $[4,8]$.

\section{Reforming reactions}

HYL in Suez steel Co. uses a direct Reduction process which does not require a reformer, $T$ his process is called ZERO REFORMER (ZR).

In the case of the HYL $Z R$ process, the reforming reactions take place inside the reactor reduction zone using metallic iron as a catalyst.

The process starts with the natural gas and steam injection or humidity addition along with the recycled gas entering to the heater and then Oxygen injection, between outlet heater and the reactor inlet, in order to increase the temperature and to initiate the partial combustion.

The theoretical flame temperature of the reducing gas reaction with oxygen is too high; therefore, around the flame $\mathrm{H}_{2} \mathrm{O}$ and $\mathrm{CO}_{2}$ can react with $\mathrm{CH}_{4}$ to produce $\mathrm{H}_{2}$ and $\mathrm{CO}$.

Partial combustion and the reforming reactions in the transfer line of HYL ZR are:

$\mathrm{H}_{2}+1 / 2 \mathrm{O}_{2} \rightarrow \mathrm{H}_{2} \mathrm{O}$

$\mathrm{CH}_{4}+1 / 2 \mathrm{O}_{2} \rightarrow 2 \mathrm{H}_{2}+\mathrm{CO}$

$\mathrm{CO}_{2}+\mathrm{H}_{2} \rightarrow \mathrm{CO} \quad+\mathrm{H}_{2} \mathrm{O}$

$\mathrm{CH}_{4}+\mathrm{H}_{2} \mathrm{O} \rightarrow 3 \mathrm{H}_{2}+\mathrm{CO}$

$\mathrm{CH}_{4}+\mathrm{CO}_{2} \rightarrow 2 \mathrm{H}_{2}+2 \mathrm{CO}$

The HYL ZR process can produce DRI with high carbon content, at values between $1.5 \%$ and 4 $\%$,by adjusting the humidity degree in the reducing gas and the natural gas injection. In the case of the HYLZR process, most of the Carbon can be found as iron carbide $\mathrm{Fe}_{3} \mathrm{C}$ [3].

$3 \mathrm{Fe}+\mathrm{CH}_{4} \rightarrow \mathrm{Fe}_{3} \mathrm{C}+2 \mathrm{H}_{2}$

Based on kinetics theory and experimental studies it has been found that process gas temperature and composition are factors which play a very important role on the kinetics of iron ore reduction. The influence of these factors is described as follows:

i. Temperature

The temperature is the variable with the greatest influence on reaction kinetics, at high temperature, reduction rates are higher and vice versa, therefore it affect metallization degree[9].

It was found that the following parameters were affecting the temperature of the process [3]
a. Process gas temperature at reactor inlet
b. Process gas temperature at heater outlet
c. Oxygen gas flow at partial combustion

ii. Process gas flow rate $\&$ composition

The highest level of reduction degree should be the equilibrium situation.

Lower flow rate cannot supply enough reducing gas to reach reaction equilibrium to realize that get lower reduction degree, Therefore it affects the metallization degree.

Every reduction reaction needs enough soaking time for the reactants to contact each other. Flow rates that higher than reaction requirement cause waste and high speed of reducing gases leading to less contact time between reactant agents. Hence, the reductions do not have enough time to finish reaction process. In addition, samples reduced at a higher flow rate contain more carbon deposited on sample surface which strongly block the reducing gases from passing through inside part of samples then cause incomplete reduction processes.

High flow rate environment contains higher amount of carbon which shows higher possibility 
to get carbon deposition. Consequently, the reduction degree of samples becomes lower under high flow rate conditions[7].

It was found that the following parameters were affecting on the Process Gas Flow rate \& Composition of the process:[3]

a. Process gas flow at reactor inlet

b. Reducing gases ratio

c. Humidity in process gas and humidity effect on reducing gases ratio

\section{iii. Cooling gases flow rate and composition}

The carburization of direct reduced iron takes place by carburization agents, among which Carbon monoxide (CO) and methane $\left(\mathrm{CH}_{4}\right)$ are the most important.

The following parameters were affect the cooling gas flow rate $\&$ composition of the process that affect the carbon content in the production [3] :

a. Natural gas flow rate to cooling zone

b. Cooling gases flow rate

It was found that the gradual increases of process parameters change the quality of the product after the residence time.

\section{E. Residence time}

The total time of a particles through the reactor three zones for complete redaction, carburization and cooling for the iron ore is called residence time. This time controls the Reactor production rate and, physically it is controlled by varying the speed of rotation of the rotary valve[3].

Relation between the reduction degree and the time at different temperatures $(850,900,950$ and $1000^{\circ} \mathrm{C}$ ) have been studied by 'Rashmi Rwnjan and Vinay'[1]. They found that the degree of reduction increases by increasing the temperature.

\section{Determination of the residence time (R.T.)}

In order to determine R.T. for Suez Steel company reactor the following equation is used :

$$
\mathrm{m}=\rho^{*} \mathrm{v}
$$

$m=$ mass of ore (DRI or Mix) (ton) $\rho=$ density of ore (DRI or Mix) (ton/m3) V= reactor volume (m3)

Fig (1) shows the different zones in the reactor which are reactor ducts, reduction \& reforming zone, isobaric zone and cooling zone and in table (1) zones volumes of Suez steel reactor with different materials.

R.T. = Reactor capacity (ton)/ production rate (ton/hr) (15)

\section{Reactor capacity= summation of $\mathrm{V}^{*} \rho$}

Where $\mathrm{V}=$ volume of material (volume of zones) $\rho=$ Density of material
Table 1 Suez steel reactor different zones volumes

\begin{tabular}{|c|c|c|c|c|c|}
\hline Zone & $\begin{array}{c}\text { Reactor } \\
\text { Duct }\end{array}$ & Reduction & Isobanic & Cooling & $\begin{array}{c}\text { Total } \\
\text { operation } \\
\text { volume }\end{array}$ \\
\hline $\begin{array}{c}\text { Volume } \\
\left(\mathrm{m}^{3}\right)\end{array}$ & 15.326 & 339.669 & 163.371 & 726.694 & 1245.06 \\
\hline
\end{tabular}

Where,

Density of iron ore $=2.2 \mathrm{ton} / \mathrm{m}^{3}$

Density of DRI=1.6 ton $/ \mathrm{m}^{3}$

Density of $\mathrm{mix}=1.9$ ton $/ \mathrm{m}^{3}$

At the beginning the reactor is filled with iron ore only. Then, it will be filled with a mixture (Iron ore + DRI) because the first two zones (reactor ducts\& reduction) will be filled by iron ore and the second two zones (isobaric \& cooling) will be filled by DRI. By applying equation (14) using data from Table (1) and density values, Table (2) shows the weights of filling materials at zones for different conditions (ore, DRI \& mix)

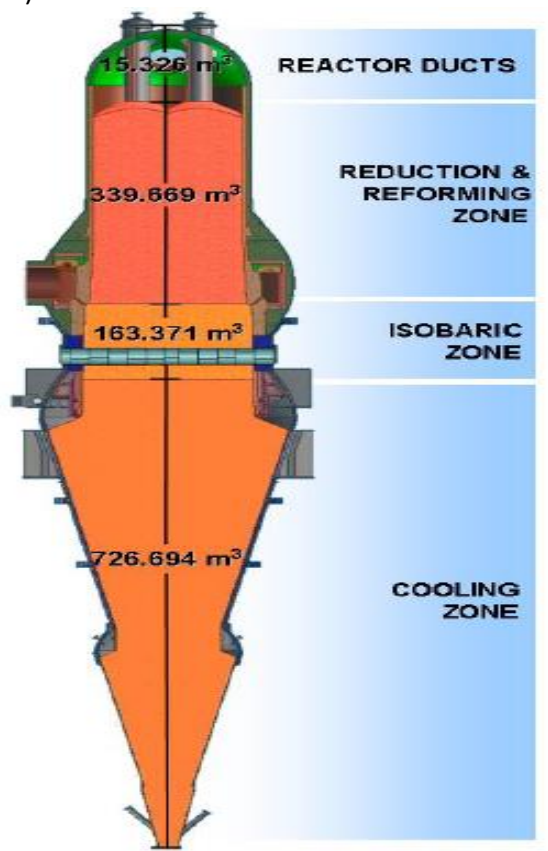

Figure 1 Suez steel company reactor different zones capacity volume[3]

Table 2 Weight of filling materials in various Suez Steel reactor zones

\begin{tabular}{|c|c|c|c|c|c|}
\hline Filling & $\begin{array}{c}\text { Reactor } \\
\text { Duct }\end{array}$ & $\begin{array}{c}\text { Reduction } \\
\text { zone }\end{array}$ & $\begin{array}{c}\text { Isobaric } \\
\text { zone }\end{array}$ & $\begin{array}{c}\text { Cooling } \\
\text { zone }\end{array}$ & Totaloperation \\
\hline ORE & 33.718 & 747.2904 & 359.425 & 1598.77 & 2739.2 ton \\
\hline DRI & 24.5229 & 543.4988 & 261.407 & 1162.77 & 1992.2 ton \\
\hline Mix & 29.12 & 645.395 & 310.416 & 1380.77 & 2365.7 ton \\
\hline
\end{tabular}

By know the production rate, equation (14) and from Table (2), it can be determine the equivalent resident time for each production rate that shown in Table (3).

If $R . T .=T$ \& production rate $=P$ so $(T=2365 / P)$

It is found that the resident time decreases with the production rate as shown in Fig (2)

Table 3 Residents times for different production rates 


\begin{tabular}{|c|l|l|l|l|l|l|l|}
\hline Production rate (Ton $/ \mathrm{hr})$ & 180 & 170 & 160 & 150 & 130 & 110 & 100 \\
\hline Resident time (hr) & 13.1 & 14 & 14.7 & 15.7 & 18 & 21.5 & 23.6 \\
\hline
\end{tabular}

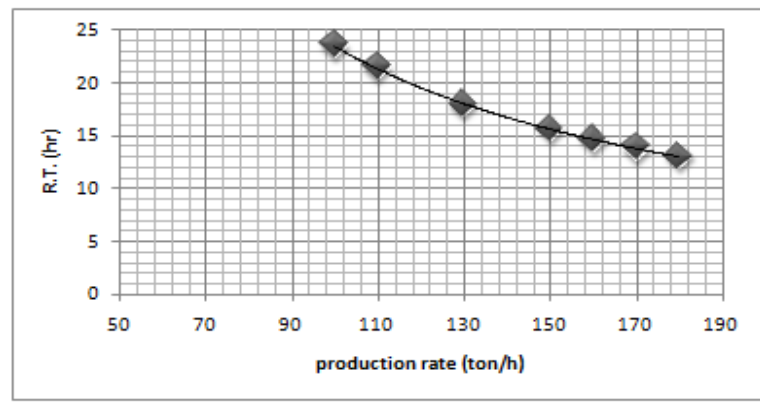

Figure 2 Relation between the resident time and production rate

\section{Results and Discussion}

DRI Quality is being mainly determined by both the Metallization and Carbon percentages so we'll discuss the main parameters affecting both of them. There is another variable of DRI quality which is important because it is closely related to metallization and it can be used as an alternative form of quality estimation. This variable is the percentage of reduction or reduction degree and it is defined as the ratio of removed Oxygen to the reducible Oxygen originally in the ore and the reduction degree is directly proportional to the metallization degree [6].

It can be represented as follows [4]:

$$
\% \mathrm{R}=\frac{\% \text { Removed Oxy gen }}{\text { Reducible Oxy gen }} \times 100
$$

\section{A. Parameters affecting Metallization degree ( $\mathrm{M} \%)$ are: \\ 1- Process Gas Temperature}

a) Process gas temperature at reactor inlet

b) Process gas temperature at heater outlet

c) Oxygen gas flow at partial combustion

\section{2- Process Gas flow rate \& Composition}

a) Process gas flow at reactor inlet

b) Reducing gases ratio

c) Humidity in process gas and humidity effect on reducing gases ratio

\section{B. Parameters affecting carbon content are:}

1. natural gas flow rate to cooling zone

2. cooling gases flow rate

\section{A. Parameters affecting Met \%}

\section{Process Gas Temperature}

The temperature is the variable with the greatest influence on reaction kinetics, at high temperature, reduction rates are higher and, vice versa. it can be said that a Direct Reduction process will be more productive as the operation temperature is higher.[4] Based on data from 'Amit Chatterjee' [4] the degree of reduction is directly proportional to temperature. It was found that the following parameters have been studied that affecting on the temperature of the process:

a) Process gas temperatures at reactor inlet

The relation between the process gas temperature at the reactor inlet and the metallization degree is shown in Fig (3). It can be observed that the metallization degree is varying from $83 \%$ up to $95 \%$ and the process gas temperature varying from $800^{\circ} \mathrm{C}$ to $1093^{\circ} \mathrm{C}$ and it is clearly shown that the metallization degree is directly proportional to process gas temperatures at reactor inlet.

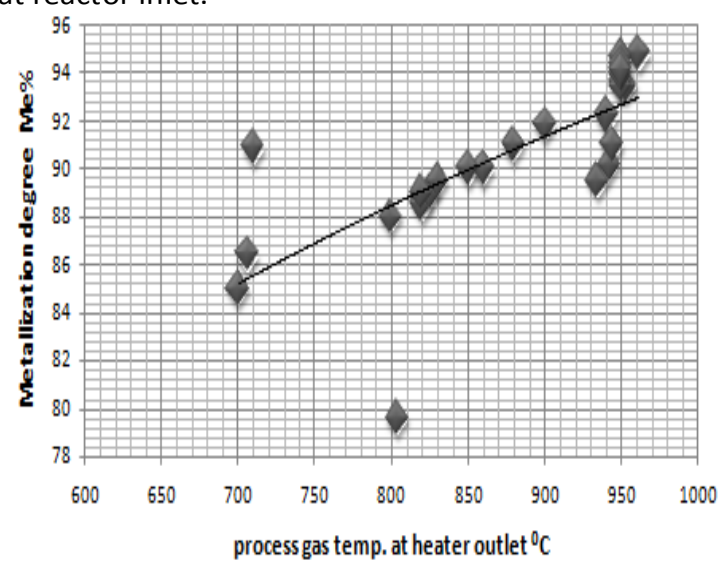

Figure 3 Relation between metallization degree and the process gas temp. at reactor inlet

b) Process gas temperatures at heater outlet

The relation between the process gas temperature at the heater outlet and the metallization degree is shown in Fig (4). It can be observed that the metallization degree is varying from $79 \%$ up to $95 \%$ and the processes gas temperature at heater outlet varying from $700^{\circ} \mathrm{C}$ to $950^{\circ} \mathrm{C}$ and it is clearly shown that metallization degree is directly proportional to process gas temperatures at heater outlet.

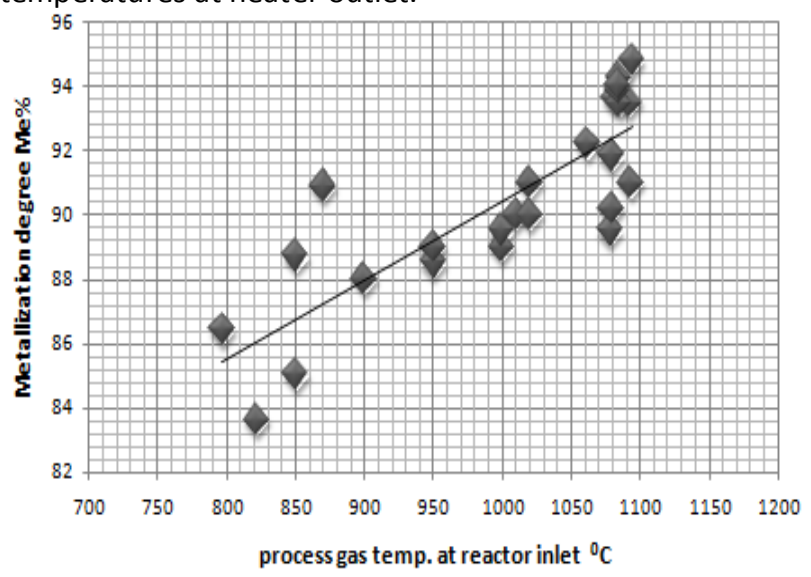

Figure 4 Relation between metallization degree and the process gas temp. at heater outlet

c) Oxygen flow at partial combustion area 
The relation between the oxygen flow at the partial combustion and the metallization degree has been shown in Fig (5). It can be observed that the metallization degree is varying from $79 \%$ up to $95 \%$ and the oxygen flow rate varying from 500 (Normal cubic meter per hour) $\mathrm{Ncm} \backslash \mathrm{h}$ to $10^{4}$ $\mathrm{Ncm} \backslash \mathrm{h}$ and it is clearly shown that metallization degree increase with the increasing of oxygen flow at partial combustion zone, the is mean that metallization degree is directly proportional to oxygen flow at partial combustion zone.

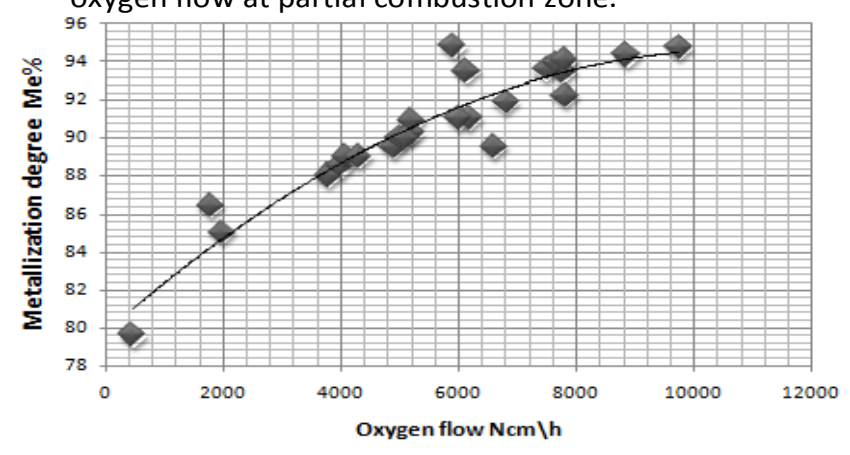

Figure 5 Relation between metallization degree and oxygen gas flow at reactor inlet

\section{2- Process Gas flow rate \& Composition}

As mentioned before the highest level of reduction degree should be the equilibrium situation.

Lower flow rate cannot supply enough reducing gas to reach reaction equilibrium so that get lower reduction degree.

The most typical components of the reducing gas are the following:

$$
\left(\mathrm{H}_{2}\right),(\mathrm{CO}),\left(\mathrm{CO}_{2}\right),\left(\mathrm{CH}_{4}\right),\left(\mathrm{H}_{2} \mathrm{O}\right) \text { and }\left(\mathrm{N}_{2}\right)
$$

With exception of Nitrogen, which is an inert gas, the remaining components of the reducing gas are reactive and they participate in different reactions, such as: reduction, carburization or others within the process. For example, the $\mathrm{CO}$ can reduce, but it can also carburize.

As it is known, the reducing gas is also utilized as fuel gases $\left(\mathrm{H}_{2}, \mathrm{CO}, \mathrm{CH}_{4}\right)$.

There are three important characteristics of a reducing gas:

\section{- Ratio of $\mathrm{H}_{2} / \mathrm{CO}$}

It is more desirable to have a reducing gas with a ratio of $\mathrm{H}_{2} / \mathrm{CO}$ greater than 3 , due to the fact that $\mathrm{H}_{2}$ has a higher reduction rate than $\mathrm{CO}$. also the velocity of reduction (rate of reduction) increased by increasing of the temperature of reducing gases specially with reduction by hydrogen [4].

The relation between reduction degree and temperature by using different reducing gases $\left(\mathrm{H}_{2}\right.$ \& $\mathrm{CO}$ ) were studied based on data from 'Amit Chatterjee' [4], and it was found that the reduction rate by using $\mathrm{H}_{2}$ gas is more than reduction rate by CO gas.

- Sum of $\mathrm{H2}+\mathrm{CO}$
Reducing gas with the largest amount of $\mathrm{H}_{2}$ plus $\mathrm{CO}$ is preferred because as the sum of the percentages of these gases increases, the greater is the reducing power of the gas.

In general, it is known that a gas with a percentage of $\mathrm{H}_{2}+\mathrm{CO}$ higher than $85 \%$ is a gas with a great reducing power.[3]

- Oxidation Degree

The oxidation degree of a reducing gas is the sum of the percentages of Carbon dioxide $\left(\mathrm{CO}_{2}\right)$ and water $\left(\mathrm{H}_{2} \mathrm{O}\right)$

These gases are the gaseous products of the reduction reactions with $\mathrm{CO}$ and $\mathrm{H}_{2}$ respectively and they represent from the standpoint of chemical potential, an obstacle for the occurrence of those reactions, so as the degree of oxidation of a reducing gas is greater, its chemical potential for reduction will be lower.

For thermodynamic and economical reasons, a reducing gas generating unit always provides a gas with a certain degree of oxidation which generally, must be lower than $10 \%$ in order to be supplied directly to the process avoiding the need of passing it through previous separating stages; for example, partial or complete cooling or partial or total $\mathrm{CO}_{2}$ absorption. [3]

It was found that the following parameters have been studied that affecting on the composition and flow rate of the process gas:

a) Process gas flow rate at reactor inlet

Figure 6 shows the relation between the process gases flow at the reactor inlet and the metallization degree. It can be observed that the metallization degree is varying from $79 \%$ up to $95 \%$ and process gas up to $35 * 10^{4}$ and the optimum flow is $3^{*} 10^{5}$ it is clearly shown that metallization degree is directly proportional to process gases flow rate at reactor inlet until optimum flow and metallization degree start to decrease and these may be due to at higher flow rate the iron ore obtained more carbon deposited on the surface which strongly block the reducing gases pass through inside part of the iron ore then caused incompletely reduction process.[7]

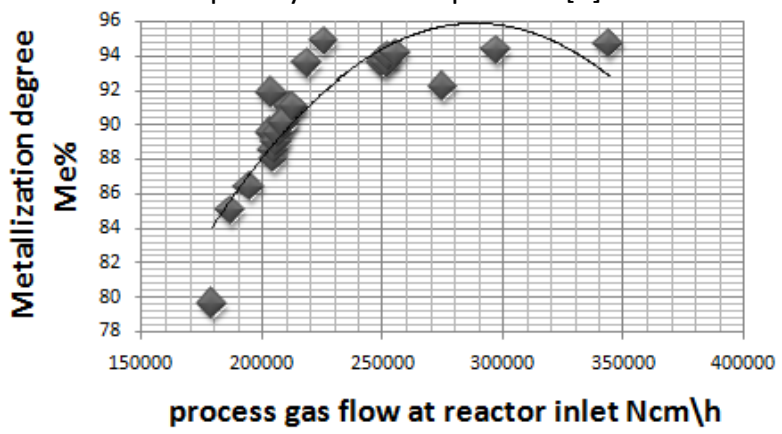

Figure 6 Relation between metallization degree and Process gas flow rate at reactor inlet

b) Reducing gases ratio

Figure 7 shows the relation between the reducing gases ratio and the metallization degree. It can be observed that the metallization degree is varying from $79 \%$ up to $95 \%$ and it is clearly shown 
that metallization degree is varying with the increasing of reducing gases ratio, this is mean that metallization degree is directly proportional to reducing gases ratio up to 5 and more than this the metallization start to decrease again and this may be due to the lack of expansion of magnetite during reduction causes the formation of dense layer of metallic iron surrounding remnants of wustite which cut off access of the reducing gas to the oxide and practically prevents complete removal of oxygen.[17]

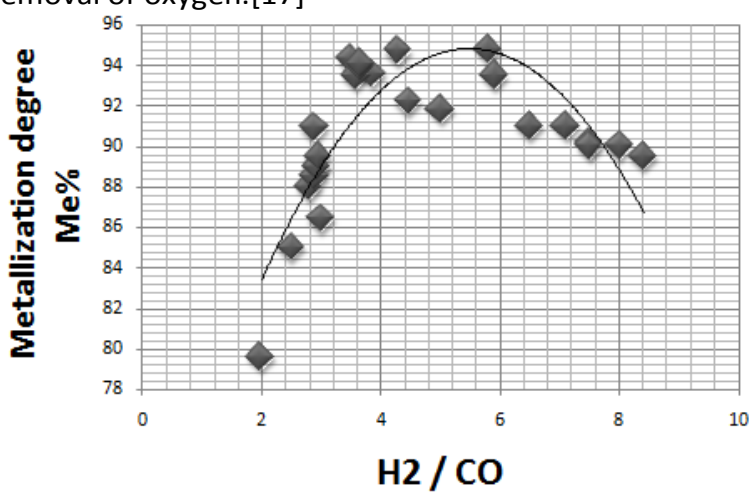

Figure 7 Relation between metallization degree and reducing gases ratio

c) Humidity in process gas and humidity effect on reducing gases ratio

Figure 8 shows the relation between the humidity $\mathrm{H} 2 \mathrm{O} \%$ and the metallization degree. It can be observed that the metallization degree is varying from $79 \%$ up to $95 \%$ and it is clearly shown, the is mean that metallization degree is directly proportional with humidity $\%$ in process gas until $6.3 \%$ humidity and then start to degrease, and this may due to humidity $\%$ is directly affected on the reducing gases ratio.

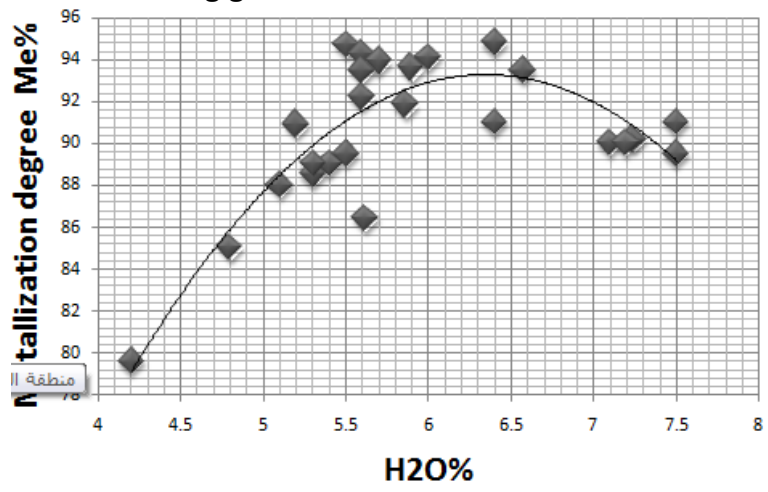

Figure 8 Relation between metallization degree and $\mathrm{H}_{2} \mathrm{O} \%$

Figure 9 shows the relation between the reducing gases ratio and the humidity $\%$. It can be observed that the reducing gases ratio $\mathrm{H} 2 / \mathrm{CO}$ is increasing with humidity $\%$ in the process gas that have direct effect on the reduction reaction of iron ore that lead to increasing in the metallization degree.

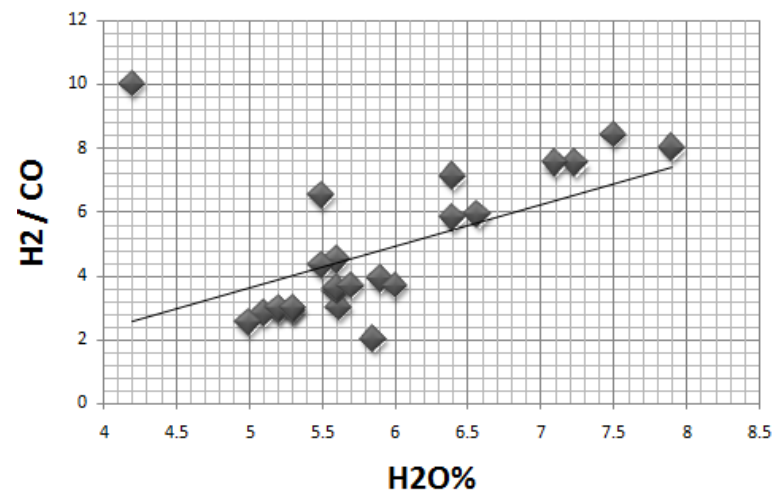

Figure 9 Relation between reducing gases ratio and $\mathrm{H} 2 \mathrm{O} \%$

\section{B. Parameters affecting carbon content are:}

It was found that the parameters affecting carbon content ( $\mathrm{C} \%)$ are as follows:

1) Cooling gases flow at cooling zone inlet (mainly CO)

2) Natural gas flow to reduction zone (mainly $\mathrm{CH}_{4}$ )

Thermodynamics and chemical kinetics show that these reactions are endothermic; for that reason, they will have a greater chemical potential to take place and a higher reaction rate at high temperatures. The carbon activity is increased with temperature and $\mathrm{CH}_{4}$ composition in the process gas according to the following reactions [10]

Carburization with CO

$3 \mathrm{Fe}(\mathrm{s})+2 \mathrm{CO}(\mathrm{g}) \rightarrow \mathrm{Fe}_{3} \mathrm{C}(\mathrm{s})+\mathrm{CO}_{2}(\mathrm{~g})$

Carburization with $\mathrm{CH} 4$

$3 \mathrm{Fe}(\mathrm{s})+\mathrm{CH} 4(\mathrm{~g}) \rightarrow \mathrm{Fe} 3 \mathrm{C}(\mathrm{s})+2 \mathrm{H}_{2}(\mathrm{~g})$

\section{Cooling gas flow rate at cooling zone inlet (mainly CO)}

Figure 10 shows the relation between the carbon content and the cooling gas flow, the carbon content as it is the second factor determined the quality of production (sponge iron) it increasing from 2.2 to $4 \%$ with increasing of carbon monoxide flow rate in cooling gas, this is mean that carbon content is directly proportional to carbon monoxide flow rate in cooling gas.

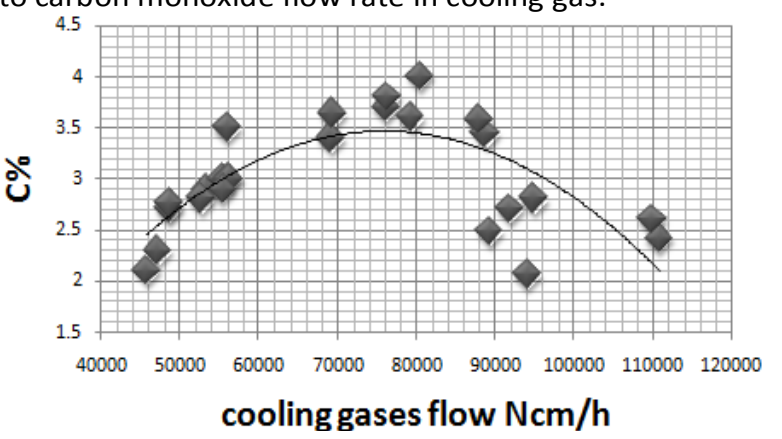

Figure 10 Relation between carbon content and cooling gases flow rate at cooling zone inlet 
2. Natural gas flow rate to reduction zone (mainly CH4)

Figure 11 shows the relation between the carbon content and the natural gas make up for cooling gas flow, the carbon content as it is the second factor determined the quality of production (sponge iron) it increasing from 2.2 to $4 \%$ with increasing of natural gas flow as a makeup for cooling gas, this is mean that carbon content is directly proportional to natural gas flow as a make-up for cooling gas.

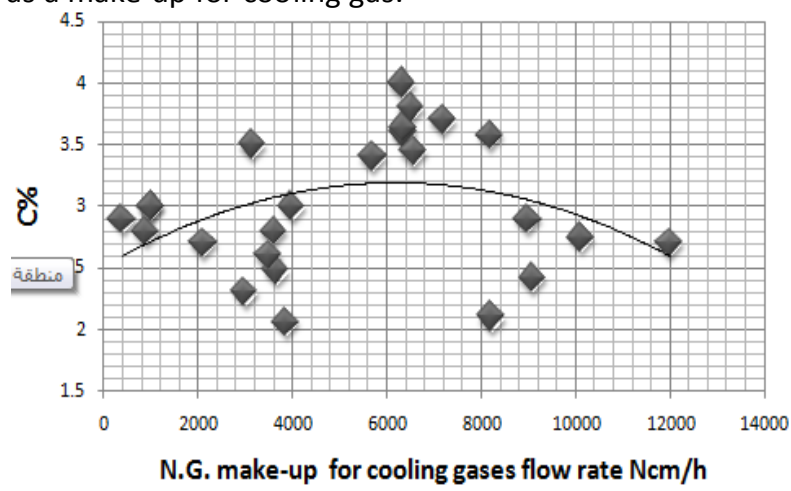

Figure 11 Relation between carbon content and natural gas make up for cooling gases

\section{Conclusion}

The processing of industrial data of HYL ZR process in Suez Steel Company for the period 2013-2014 leads to the following conclusions. The quality of DRI is determined by two main properties which are the degree of metallization and carbon content. They could be obtained by the following parameters

A. A desirable metallization percentage of $94.7 \%$ could be realized by applying:

1- Temperature of $1093{ }^{\circ} \mathrm{C}$ for gas at reactor inlet while $950^{\circ} \mathrm{C}$ for heater output.

2- Reducing gas ratio $\left(\mathrm{H}_{2} \% / \mathrm{CO} \%\right)=5.5$ while humidity degree $=6.3 \%$

3- Gas flow rate of $3 * 10^{5} \mathrm{Ncm} / \mathrm{hr}$ for process gas and $10^{4} \mathrm{Ncm} / \mathrm{hr}$ for oxygen in partial combustion.

B. An acceptable carbon content of about $4 \%$ could be attained at the following gas flow rates:

For cooling gas (mainly CO) it is $8 * 10^{4} \mathrm{Ncm} / \mathrm{hr}$ while for N.G make up (mainly $\mathrm{CH} 4$ ) $6 * 10^{3} \mathrm{Ncm} / \mathrm{hr}$
[4] AMIT CHATTERJEE-2012- SPONGE IRON PRODUCTION BY DIRECT REDUCTION OF IRON OXIDE- chapter 3

[5] Faccone, 1984, united states patent (Direct reduction of iron)

[6] Ministry of Environment and forests, Govt . of India- Parivesh Bhawan, East Arjun Nager 2006- sponge iron industry.

[7] Wu Yunyun ,2012, Effect of different parameters on the direct reduction processes of natural iron oresfrom Uganda

[8] J. Feinman, President, J. Feinman and Associates, Inc. (Retired U.S. Steel Corp.),Direct Reduction and Smelting Processes, Iron making Volume, Chapter 11

[9] Brain C. Cunningham, Hamerskey iron Pty. Limited and James G. Stephenson, Kasier Engineering Inc. - DRI-Technology and economics of production and use chapter 6(Direct reduction processes).

[10] A, Serna and R»A. Rapp, Carburization of austenitic and ferritic alloys in hydrocarbon environnnents at high temperatures,2003

[11] Olga Karabelchtchikova, Fundamentals of Mass Transfer in Gas Carburizing, 2007

[12] Dominguez- ahedo et al.- 1983- united states patent (method for the gaseous reduction of iron ore to sponge iron)

[13] Altenhoner et al.1977- united states patent (Process for the production of sponge iron)

\section{References}

[1] Rashmi Rwnjan Pati and Vinay M - 2008 Reduction Behavior of iron ore pellets.

[2] J.fetnman, president, J.feiman and a Association, Inc. (Retired u.s steel corp.)-1999 Different methods for produce DRI (chapter 11 Direct Reduction and smelting process )

[3] HYL Process analysis training informative course - 2011 Module 6-Mexico, Monterrey 